\title{
García Hurtado de Mendoza ¿Gobernador o Héroe?
}

\author{
Remedios Morán Martín *
}

Durante el curso 1982-83 la Universidad de Córdoba tenía una oferta de cursos de doctorado limitada, pero de alta calidad. Entre ellos elegí dos que sin tener una relación directa con los temas que hasta entonces había estudiado, influyeron decididamente en mí. Me refiero a los de los profesores Avilés Fernández: «Historia social de la producción de libros en la España Moderna" y Alonso Seoane: "La trayectoria del Romanticismo literario a través de la novela española del siglo XIX" ".

Aprendí entonces que detrás de una obra de literatura puede plasmarse una ideología que, por una parte, se relaciona con el género literario en el que se presenta, que está unido al efecto que quiere producir su autor, $y$, por otra, que hay que interpretar dichos textos en relación con otras coordenadas que van más allá de las puramente estéticas, puesto que en ellas puede subyacer la crítica socio-política ${ }^{2} 0$, como en el caso que estudiamos, la justificación de una actuación, siempre incardinada en un momento histórico.

Sirvan estas páginas como reconocimiento.

UNED. Madrid.

Desde estas páginas quiero agradecer a la profesora M. ${ }^{\mathrm{B}}$ José Alonso Seoane sus indicaciones para el encauzamiento de los trabajos que dentro del amplio campo de la relación entre el Derecho y la Literatura he abordado, tanto en temas americanos, como especialmente, en el estudio de la obra de JovelLANOS, El delincuente honrado, sin cuyas observaciones y aportación bibliográfica no hubiera podido realizar (MORÁN MARTíN, R., «La reforma del derecho penal en el pensamiento de Jovellanos y posible influencia en Lardizábalm, en Anuario Jurídico y económico escurialense, núm. XXVI, vol. II (1993), págs. 471-498).

2 Vid. Avilés FernánDEZ, M., Sueños ficticios y lucha ideológica en el Siglo de Oro. Madrid 1980. 


\section{PLANTEAMIENTO DEL TEMA}

Tras los primeros viajes a América los personajes que habían participado en ellos como marineros, conquistadores, funcionarios o sacerdotes difundían historias donde la realidad y la fantasía se aunaban para dar una imagen de riqueza y abundancia que se corroboraba con la imagen del "indiano" enriquecido que volvía a su tierra y formaba una clase de nuevos ricos que emparentaban con la burguesía o la nobleza vieja venida a menos. Pero paralelo a esto, se estaba produciendo una reorganización de instituciones para adecuar las ya existentes a la nueva realidad presentada tras el descubrimiento y conquista de América y a nivel intelectual se cuestionaba la conquista y el trato que debía darse a la población allí asentada antes de la llegada de los españoles.

El reflejo en la literatura de este proceso es escaso, sin embargo se aprecia un interés por parte de los conquistadores por dar a conocer sus hazañas en el nuevo continente, interés que a veces está guiado por el afán de conseguir cargos y prevendas, otras veces por difundir la justificación de sus hechos, utilizando la literatura como cauce para crear una conciencia popular, que a su vuelta a la península, le favoreciera en las posibles reivindicaciones que plantearan a la Corona; caso que veo con claridad en las obras que se centran en la figura de Cortés del que se intenta crear la imagen del conquistador que actuó en todo momento dentro de la legalidad vigente ${ }^{3}$ o en el caso de Los Pizarro, principalmente a través de la Trilogía de los Pizarro, de Tirso de Molina ${ }^{4}$ que pretende difundir la idea de un Gonzalo Pizarro que rechazó la corona del Perú por mantenerse fiel a la autoridad real ${ }^{5}$ y que se escribe para conmemorar la creación del título de marqués de la Conquista ${ }^{6}$.

Dentro de este tipo de obras que pretenden rehabilitar la figura de alguno de los conquistadores considero que puede estar la amplia producción literaria que se crea en torno a García Hurtado de Mendoza,

3 Vid. Pérez-Prendes, J. M., «Los criterios jurídicos de Hernán Cortés», en Actas de/ / congreso Internacional sobre Hernán Cortes. Salamanca 1986, 209-239.

"Tirso de Molina "Todo es dar en una cosa" (1626-1630), "Amazonas en las Indias" (1629 ó 1632) y “La lealtad contra la envidia» (1626-1630), en Obras dramáticas completas. (Ed. crítica por Bianca de los Ríos), tomo III, 643-792. Sobre la justificación literaria de la actuación de los Pizarro en América, vid, MEdinA, J. T., La Historia de América, fuente del antiguo teatro español. Santiago 1917, págs. 32-69.

5 Tirso de Molina, Amazonas en Indias, op. cit.

- Fernández, T., "La imaginación americana en el teatro de Tirso de Molina", en Edad de Oro, $X$ (1991), pág. 88 , nota 7 , autor que también considera que la trilogía de Tirso de Molina intenta restituir la honra de los Pizarro y la imagen perdida de su lealtad al rey. 
analizando el porqué de su plasmación en obras de literatura con mayor intensidad a lo que habían sido los hechos de otros personajes que habían intervenido en la conquista y colonización del nuevo mundo, formando paralelo con las obras que se inspiraron en la figura de Cortés ${ }^{7}$.

En este sentido, creí interesante profundizar en uno de los aspectos: el tratamiento de la figura de García Hurtado de Mendoza en las obras más relevantes que tratan sobre la conquista de Chile, la descripción de su actuación, de las competencias que tenía en el ejercicio de su cargo, el análisis de su ideario político, etc.

No es mi objetivo en este estudio sacar a la luz obras desconocidas que nos vayan a aportar una nueva visión sobre el tema de América en la literatura del Siglo de Oro, labor que en su mayor parte ha sido hecha por filólogos, sino releer las principales obras que recogen la actuación de Hurtado de Mendoza como gobernador de Chile, tratando de hilvanar las causas de la imagen que se pretende dar de este personaje.

En este punto se tendría que deslindar, en primer lugar, si algunas de las obras consideradas crónicas lo son en su totalidad o en sus páginas se encuentran filtradas escenas que más bien se pueden considerar de pura ficción, tema que cobra un relieve especial en el caso de los relatos de Andrés y García Hurtado de Mendoza. Leyendo crónicas, poemas épicos y obras de teatro sobre este último personaje se tiene la impresión de que se asiste a una verdadera "guerra de textos» para realzar la labor de don García en América.

Ya Andrés Hurtado de Mendoza había utilizado las letras como segunda arma de su actuación en el nuevo mundo, por ejemplo, nombrando a Diego Fernández Cronista del Perú ${ }^{8}$. Posteriormente su hijo, D. García,

Sobre la figura de Hernán Cortés en la literatura, vid. REynolds, W. A., Hernán Cortés en la literatura del Siglo de Oro. Madrid 1978; AMOR y VÁzQUEZ, J., "Hernán Cortés en dos poemas del Siglo de Oro", Nueva Revista de Filología Hispanica, XI1, 3-4 (julio-diciembre, 1958), págs. 368-382. MEDINA, J. T., Ensayo bio-bibliográfico sobre Hernán Cortes (obra póstuma)(introducción de Guillermo Feliu Cruz). Santiago de Chile 1952. Carlo Famoso. El prim de Winston A Rey del descubrimiento y conquista del nuevo mundo, de Luis Zapata, (Edicior nolds). Madrid 1984

Hasta que fue destituido y vuelto a nombrar para similar tarea por D. Francisco Tello de Sandoval, interesado en justificar su propia actuación en relación con su oposición a la aplicación de las Leyes Nuevas y las consecuencias de su aplicación en cronistas para justificar Historiografía indiana. Madrid 1964, págs. 426-27. La utización desconocida, por no salirme del espacio hechos de los conquistadores no es práctica extrana ni desconocida, PANCHO, Pedro, Relación de peruano, tómese como ejemplo la obra del secretario de Pizar Joaquín García Izcabaleta Madrid la conquista del Perú (versión castellana con anotaciones 1962. 
utiliza también a cronistas para difundir su imagen encargando a Bartolomé de Escobar la reelaboración de la obra de Mariño de Lobera, que adaptó al gusto de su protector, después utilizada como fuente por su apologista, Suárez de Figueroa y posteriormente se inspirarían en ella de forma directa $o$ indirecta Luis de Belmonte y sus colaboradores y el mismo Lope de Vega ${ }^{9}$.

Por lo tanto, literatura y crónicas se dan la mano en muchos de sus ragos fundamentales, que aquí deben tenerse en cuenta al esbozar la imagen que García Hurtado de Mendoza quiso difundir de sí mismo, tarea en la que lo secundó su hijo. Es la imagen del hombre religioso, por encima de todo, generoso con el enemigo al mismo tiempo que enérgico, valeroso en la guerra, consciente y orgulloso de su estirpe..., atributos que encajaban perfectamente en el héroe de los poemas épicos y de los protagonistas de comedias en el siglo XVI y XVII. Sin embargo ino es ésta la forma de crear la imagen de un héroe popular más que una verdadera reivindicación de la figura de un militar y un político que era la realidad histórica de García Hurtado de Mendoza? La literatura, incluso las crónicas, son parcas al esbozar la actuación administrativa y la ideología de D. García, teniendo que bucear en miles de versos y descripciones de escenas bélicas algún dato que nos caracterice a este gobernador y virrey de Chile y Perú, respectivamente.

El análisis de esta faceta es la que se aborda en este trabajo.

9 Las principales obras que recrean la figura de García Hurtado de Mendoza, según las ediciones por las que se citan son:

- Crónica del reino de Chile, escrita por el capitán D. Pedro Mariño de Lobera, dirigida al excelentísimo Sr. D. Garcia Hurtado de Mendoza, Marqués de Cañete, Vicerrey y Capitán General de los Reinos del Perú y Chile, reducido a nuevo método y estilo por el Padre Bartolomé de Escobar, de la compañia de Jesús (Ed. B.AA.EE., tomo CXXXI. Madrid 1960).

Christóval Suárez de Figueroa, Hechos de Don Garcia Hvrtado de Mendoça, cuarto marques de Cañete. Madrid 1613.

- Pedro de Oña, Primera parte de Arauco Domado, (Ed. B.AA.EE., tomo XIX. Madrid 1948, 351-456).

- Luis de Belmonte y otros: Algunas hazañas de las muchas de Don García Hurtado de Mendoza, marqués de Cañete (Ed. B.AA.EE., Tomo XX. Madrid 1946, 489-508).

- Lope de Vega, Arauco Domado por el Excelentísimo señor D. Garcia Hurtado de Mendoza (Ed. B.AA.EE., Tomo XXVII, Madrid 1969, 233-289).

- Gaspar de Ávila, El gobernador prudente (Ed. MEdinA, J. T., Dos comedias famosas y un auto sacramental. Santiago-Valparaiso 1915). 


\section{GARCIAA HURTADO DE MENDOZA: UN FUNCIONARIO CON PRETENSIÓN DE HÉROE DE POEMAS Y COMEDIAS}

\section{Intentos de explicación}

Necesariamente hay que partir de La Araucana, de Alonso de Ercilla, para comprender la avalancha de obras que intentan contrarrestar la imagen que este autor dio de D. García. Se ha dicho hasta la saciedad que Ercilla creó intencionadamente un poema sin héroe, pretendiendo minimizar la figura de Hurtado de Mendoza, como venganza de la injusta condena a muerte a causa de un incidente en La Imperial, posteriormente conmutada ${ }^{10}$. Una segunda teoría sobre el tema aboga por la plasmación en La Araucana de las ideas indigenistas de su autor ${ }^{11}$. Posiblemente la más novedosa de las posturas sea la defendida por Enrique de Gandía que considera a La Araucana un alegato encubierto en contra de la conquista de Navarra por Fernando el Católico, estableciendo un símil entre aquella dominación y la del pueblo araucano, una y otra forzada en contra del pueblo y sin justa causa ${ }^{12}$.

Respecto a la primera postura, realmente en La Araucana D. García apenas se menciona, pero cuando se hace, excepto en una ocasión, su imagen no resulta menoscabada, e incluso en ésta, cuando lo califica de "mozo capitán acelerado", no hace sino reseñar un rasgo de su carácter que va a aparecer con frecuencia en su actuación como gobernador de Chile, dejándose llevar en ocasiones por un ímpetu juvenil que le haría después rectificar su impulso inicial.

En cuanto a las ideas indigenistas del autor de La Araucana considero que no contradice ninguna de las restantes posiciones y que aparece clara en su obra en cuanto a plasmación de una idea, si bien, como analiza

10 Menéndez Pelayo, M., Historia de la poesía hispano-americana. Madrid, MCMXLVIII, tomo II, 237. Vega Garcia-Luengos, G., «Las hazañas americanas de García Hurtado de Mendoza en una comedia de nueve ingenios. El molde dramático de un memorial», en Edad de Oro (Madrid), $X$ (1991), pág. 200.

"Campos Harriet, F. Don García Hurtado de Mendoza en la Historia americana. Santiago de Chile 1969, págs. 196 y ss. Para Morínigo más que una postura indigenista, se trata de la elevación del indio araucano a la categoría de superhombre, como recurso poético, "en un poema histórico con mucho de poema y poco de historia", además, engrandeciendo al enemigo, engrandecía a los españoles, Morínigo, M. A., Introducción en Ercilla, Alonso de, La araucana (Edición, introducción y notas de Marcos A. Morínigo e Isaías Lerner. Madrid 1991, I, págs. 33,38 y passim.

12 GandíA, E. de, "Los fines políticos y teológicos de La Araucana de Ercilla", en Boletín del Instituto Americano de Estudios Vascos (Buenos Aires), vol x, n. ${ }^{\circ} 36$ (oct.-dic., 1959), págs. 155161. 
Morínigo, en ella no aparezcan términos indígenas en la medida que el tema lo requería. Sin embargo, esto no debe ser óbice para el "olvido" de $D$. García, porque leyendo las obras que pretenden reivindicar a éste también se aprecia el mismo sentimiento, presentando al pueblo araucano como paradigma del hombre naturalmente bueno, defensor a ultranza de su libertad y de su identidad de pueblo, de tal modo que sin menospreciar al gobernador español (no puede decirse lo mismo de su ejército), el pueblo araucano se presenta en igualdad de valores con su oponente.

El resentimiento por la conquista de Navarra también pudo estar en la mente del autor, de origen navarro, pero posiblemente sería forzar demasiado el texto y en este caso la postura oficialista que representaría el gobernador (y sus soldados) tendría que haberse representado con mayor dureza, resaltando los aspectos negativos de su actuación ${ }^{13}$; Ercilla podría haber utilizado más enérgicamente la crueldad con que $D$. García reprimió a los araucanos en ciertos momentos, como la amputación de manos a los prisioneros, del que Galvarino se convierte en su máximo exponente, - podría haber eludido escenas como la descripción de la batalla de Lepanto (cantos XVII y XVIII), las referencias al asalto de San Quintín (canto XXIV) o la jornada de Portugal (canto XXXVII con el que termina la obra), con un entusiasmo lejos del rechazo e incluso de la indiferen$\mathrm{cia}^{14}$. Si procedió de esta forma, y teniendo en cuenta que sin exaltar a Hurtado de Mendoza, tampoco lo critica y que los españoles, a pesar de ser puestos en tela de juicio en muchas ocasiones, sin embargo la impresión general es de valentía comparable a la araucana ino podría pensarse que Ercilla considerara, que a pesar de las diferencias que los separaban, especialmente después de la condena en la Imperial, Hurtado de Mendoza y él compartían ideas comunes en cuanto al tratamiento de indios y la justificación de la guerra? En este sentido Ercilla luchó con la pluma elevando a la categoría de héroe el pueblo araucano, incluyendo en su poema continuos alegatos por la libertad y autodeterminación de esta nación y al rechazo, encubierto, del dominio español, terminando por adjuntar una especie de declaración de principios sobre la guerra en la tercera parte de la obra. Hurtado de Mendoza con sus órdenes protegió

13 Sin profundizar en que de sus versos se desprende el ánimo por conseguir favores reales, Vid., Morínigo, M. A., Introducción..., 26-27, 47. Avalle-AfCe, J. B., Dintorno de una época dorada. Madrid 1978, 37 y especialmente el cap. 7. págs. 173-191, donde defiende la manipulación de la realidad para conseguir un plan previamente establecido.

${ }^{14}$ Estas escenas han llevado a Lerner a la conclusión de que La Araucana «se habría de convertir en un texto exaltador del imperio" LEANER, I., "América y la poesía épica aúrea: La versión de Ercilla», en Edad de Oro (Madrid), X (1991), págs. 125-128. 
el trabajo de los indios en las minas $y$, sin perder de vista el ejercicio de su cargo, procuró atemperar la crueldad de la guerra.

Pero el hecho es que a partir de la publicación de la obra de Ercilla se desata una guerra de obras que vienen a reivindicar el papel de Hurtado de Mendoza del olvido que tanto él como su familia consideraban había sido objeto en La Araucana, en este punto me pregunto iqué olvidó Ercilla que tanto interés tenían los Hurtado de Mendoza en recordar al público ausente?

2. García Hurtado de Mendoza: enclave en el que ejerció el cargo de gobernador de Chile

Los hechos: Desde años atrás en la zona se vivía un ambiente de guerra entre almagristas y pizarristas que se saldó con la muerte de Francisco de Pizarro; la promulgación de las Leyes Nuevas que provoca un levantamiento popular en Perú; tras la muerte de Jerónimo de Alderete, nombrado por la Corona gobernador de Chile se asiste a la pugna entre Francisco de Villagrán (corregidor y justicia mayor del reino, nombrado por la Audiencia de Lima) y Francisco de Aguirre (general) por la gobernación. Socialmente, los encomenderos pretenden sacar el máximo beneficio de los indios, a los que acosan con trabajos excesivos en las minas y con el cobro de altos impuestos. Por otra parte, los indios de Arauco y Tucapel se rebelan contra los españoles, consiguiendo la derrota y muerte de Valdivia. En estas circunstancias el virrey de Perú, Andrés Hurtado de Mendoza, nombra gobernador de Chile a su hijo García, el 9 de enero de $1557^{15}$.

Las ideas: A estos tres frentes (restos de fracciones contrapuestas, lucha por el poder entre los dos máximos representantes de la zona y guerra con Arauco), se suma el frente ideológico que en estos momentos mantiene una tensa polémica sobre el trato de los indios iniciada a raíz de las denuncias de Bartolomé de las Casas y la controversia sobre la legitimidad de la conquista y justicia de la guerra, entablada por la Escuela de Salamanca, y que Hurtado de Mendoza vivió de cerca, al producirse precisamente a raíz de la muerte de Francisco Pizarro y la promulgación de las Leyes Nuevas ${ }^{16}$ y al contar entre sus personas más próximas a

15 Campos Harriet, F., Don Garcia Hurtado..., págs. 45-47

16 Escuela de Salamanca, Carta magna de los indios. Fuentes constitucionales. 1534-1609, Colección Corpus hispanorum de pace, vol. XXVII. Madrid 1988, VIII y 7-8. 
clérigos de ideas enfrentadas sobre estos temas, como Fray Gil de San Nicolás y Fray Juan Gallego ${ }^{17}$.

La actuación: La «Instrucción al virrey del Perú, Marqués de Cañete, sobre lo de las poblaciones y nuevos descubrimientos", de 3 de mayo de 1556, debió estar presente en la actuación de su hijo, García Hurtado de Mendoza, al hacerse cargo de la gobernación de Chile al año siguiente, de modo que desde un principio intentó una vía de acercamiento pacífico a los indios que no dio resultado en el caso de los araucanos, que pronto reanudan la guerra. En el mismo sentido, a nivel administrativo reguló el régimen de explotación de las minas, suavizando el trabajo especialmente de mujeres y niños y ampliando los derechos de los indígenas sobre la producción. Políticamente inició su mandato haciendo prisioneros a Villagrán y Aguirre, con el fin de no tener abierto un posible flanco de tensión interna, además del de los encomenderos.

\section{DON GARCÍA HURTADO DE MENDOZA EN LA LITERATURA}

La Araucana se centra en los aspectos bélicos de la guerra con los araucanos, deteniéndose principalmente en este pueblo. Éste pudo ser el motivo por el cual los textos que pretenden reivindicar la figura allí olvidada de Don Garcia se centren también en las hazañas del ejército español, con incursiones en temas araucanos más esporádicamente y casi siempre ajenos al mundo institucional. En ellos Don García se desdibuja como político y como funcionario para convertirlo en un héroe que no llega a convencer.

No obstante, detrás de este héroe de poemas y comedia, se puede esbozar parte de su pensamiento y de las actuaciones que desarrolló como gobernador de Chile (porque su labor posterior como virrey del Perú apenas se desarrolla). Entre estos aspectos pueden destacarse los relativos a la prisión de Aguirre y Villagrán, versificados según la versión de Mariño de Lobera ${ }^{18}$, posiblemente a través de la obra de Suárez de Figueroa, que trata de justificar la acción de Don García por «algunas bizarrías de Francisco de Villagran, no sin assomos de libertades y barruntos de poca fidelidad" ${ }^{19}$; las sucesivas poblaciones que fundó o re-

17 Campos Haraiet, F., Don Garcia Hurtado de Mendoza..., págs. 69-71.

18 Mariño de Lobera-Bartolomé de Escobar, Crónica del reino de Chile 366-338. Pedro de Oña: Arauco Domado, pág. 305. Lope de Vega: Arauco Domado, pág. 240. Gaspar de Ávila, El gobernador prudente, págs. 58-9.

19 Christoval Suárez de Figueroa, Hechos de Don García Hurtado de Mendoça, págs. 27. 28, sigue casi literalmente a Mariño de Lobera, si bien con seguridad utilizó un manuscrito y 
pobló; los descubrimientos que se hicieron bajo su mandato o los triunfos en expediciones como las realizadas contra el corsario inglés ${ }^{20}$; sin embargo interesa destacar ciertos aspectos de su gobernación y posterior virreinato: el trato a indios, la legitimidad de la conquista y la idea de la guerra.

1. El trato a indios: La confusa situación que vivia Chile motivó el nombramiento de D. García, tras la muerte de Alderete, la primera medida que tomó para resolver la situación será reunir a los encomenderos inmediatamente de su llegada a la Serena y hablarles sobre la necesidad de un cambio en el tratamiento a los indios y la disminución de las contribuciones:

«tutores deuen ser, no vsurpadores de sus bienes. Propios son de tales menores. Dioselos alli quien repartio en las otras prouincias todo lo demas; $y$ assi se les deue la entrega dellos, solo con titulo de vassallage, no de esclauitud. Por otra parte no falta quien quiera, sea natural la servidumbre de algunos. (...) excluyanse excesos, fenezcan desaforadas imposiciones, y sobre todo, desterrad de vuestros pechos la codicia" ${ }^{21}$.

Igualmente trata sobre las condiciones de trabajo que realizaban en minas, que había causado estragos en la población lo que consideraba "gran lastima y error, pues de su muchedumbre penden vuestras riquezas" ${ }^{22}$.

A este discurso seguirá la redacción de las Ordenanzas de minas, conocidas como Ordenanzas de Santillán, promulgadas en Concepción, el 20 de enero de 1559, cuyo contenido recoge ampliamente Suárez de Figueroa y versificado por Pedro de Oña. Las ordenanzas se resumen en los siguientes puntos:

- Que los encomenderos se valiesen sólo de la sexta parte de los indios de su encomienda para labrar las minas.

- Que sólo trabajaran en minas hombres de 18 a 50 años.

- Que del oro que se sacase se diese al indio la sexta parte "como en retribución de su mismo tributo».

fue la obra de Suárez de Figueroa la que circuló como una crónica que utilizaron como principal fuente todos los autores que escribieron sobre Hurtado de Mendoza, en este caso concreto es clara la referencia de Lope de Vega.

${ }_{20}$ Pedro de Oña, Arauco domado..., cantos XVIII-XIX. Lope de Vega, La dragontea (Ed. Federico Carlos Sainz de Robles, Tomo II. Madrid 1973, 339-411)

${ }_{21}$ Suárez de Figueroa, Hechos... pág. 23: Gaspar de Ávila, El gobernador prudente, págs.

53-54. Pedro de Oña, Arauco domado, pág. 363.

${ }^{22}$ Ibidem, pág. 24. 
- Que el reparto se hiciese el sábado (con lo que se evitaría que estuvieran el domingo esperando la paga).

- Que en las minas se pusieran como alcaldes a hombres de buena intención que no permitiesen molestias y malos tratos a los indios.

- Que los bastimentos para los obreros no se llevasen a cabo a hombros de mujeres, como se hacia hasta ahora, sino con bestias, a cargo de los vecinos.

- Que cada día se le diese a cada indio comida bastante y carne tres días a la semana, así como ropa, a cuenta de lo que le tenía que tocar.

- Que los encomenderos se abstuvieran de pedir a los indios cualquier cosa, sabiendo que no tenian más caudal que su trabajo.

- Que en los pleitos de los súbditos se interpusiera el amo como juez, sin usurparles la cosa sobre la que tuvieran diferencia. castigos.

- Que trataran de educar a los indios con buenos tratos y no con

- Que no se les hiciera trabajar los domingos y fiestas por ningún motivo, sino que por el contrario procuraran que no perdieran la misa y otros oficios cristianos, los que lo fuesen ${ }^{23}$.

En parte se recogía el sistema de mitas establecido por los incas, sistema que conocía bien su más directo colaborador, Hernando de Santillán, que, a raíz de una Cédula Real de 26 de diciembre de 1553, había elaborado un memorial sobre las costumbres, conquistas y otros asuntos relacionados con los incas, en el que trata especialmente el sistema tributario incaico y las conquistas que este pueblo hizo de las zonas circundantes, dentro de la serie de relaciones sobre estos temas encaminadas a probar que los territorios conquistados por los españoles no siempre habían sido de los pueblos allí asentados, sino que los poseían por derecho de conquista ${ }^{24}$, lo que no obsta para que Santillán demostrara en el informe la admiración que sentía hacia este pueblo y denunciar el trato de los españoles

«porque aquellos que debieran haber sido espejo y dechado de vida virtuosa y correccion y enmienda y de los soberbios y poderosos, y consuelo y reparo de los pobres y opresos, muy al contrario lo han usado, en tanto grado que con justa razon se querella aquella república" ${ }^{25}$.

${ }^{23}$ Suárez de Figueroa, Hechos... pág. 25. Pedro de Oña, Arauco domado..., págs. 363-64.

${ }^{24}$ Fernando de Santillán, "Relación del origen, descendencia, política y gobierno de los incas", en Tres relaciones de Antiguedades peruanas. Asunción del Paraguay 1950, págs. 33131.

25 Ibidem, pág. 37. 
A lo largo de los versos de las obras sobre Hurtado de Mendoza en distintas ocasiones se recoge el intento de aplicar un buen trato a los indios (lo que hace flaquear el ánimo a los araucanos, incluso, considerando la posibilidad de dejar las armas y someterse a los españoles), aspecto en el que no consigue que se ponga en práctica sus instrucciones, por la insistencia con que se reitera este tema en la legislación posterior ${ }^{26}$.

\section{Legitimidad de la conquista y "guerra justa"}

En todas las obras, sin embargo, se recoge quizás el aspecto más interesante de la actitud de Don García y de los araucanos sobre la legitimidad de la conquista y el sentido de la guerra, que termina por inclinar la balanza en favor de la continuación del litigio, con independencia del final, provisional, de sumisión a la muerte de Caupolicán, con la que concluyen varias de las obras analizadas.

La Araucana es un canto de libertad del pueblo araucano. Arauco Domado, de Pedro de Oña y Lope de Vega, así como El gobernador prudente, de Gaspar de Ávila y Algunas hazañas de las muchas de Don García Hurtado de Mendoza, de nueve autores, intentan ser el reverso de la moneda, pretendiendo resaltar la actuación de Don García. Sin embargo La Araucana ya había creado el mito del pueblo araucano como paradigma de la lucha por la libertad y ninguno de los autores siguientes intenta derribarlo ${ }^{27}$. Por este motivo el planteamiento de la legitimidad de la conquista y los motivos que los españoles tienen para ello es una constante que se recoge en todas las obras:

(...) «por el estado Araucano,

perdóname (el más anciano

soy) vengo a decir,

si aquí es justo introducir

vuestro imperio soberano.

(...) que razón

${ }^{26}$ Cedulario indiano recopilado por Diego de Encinas (Reproducción facsímil de la edición única de 1596, con estudio e índices de Alfonso Garcia Gallo, tomo IV. Madrid 1946), págs. 315 y ss.

Salvo Pedro de Oña, que a pesar de ser el único nacido en el nuevo mundo en su obra el indio queda en una posición muy inferior al del resto de los escritores, más inclinados a la visión ercillana o lascasiana de la visión del indio, postura explicable porque intenta ser la contraposición a Ercilla, lo que no supone que logre erradicar la visión idealista del indio, que también recoge de éste. 
fuera de injusta intención, os determina y consiente desta región de Occidente tan amplia jurisdicción?

Si aquel primer hombre Adán, como decís en su afán libre el mundo poseyó, mostrad por donde os dejó

la tierra en que otros están” ${ }^{28}$.

Se presenta en un principio la contraposición entre el desmesurado interés de los españoles por conseguir riquezas, que se traduce en las arengas de los caciques araucanos para levantar al pueblo contra los españoles, y en los gritos de guerra que lanzan contra ellos ${ }^{29}$ justificando la guerra en la defensa de su libertad, tanto para en el aspecto temporal

28 Gaspar de Ávila, El gobernador prudente, pág. 71.

29 «Cobardes, esperad; teneos, ladrones,

volved por el tributo que se os debe

$Y$ á recebir la paz que os da la tierra,

pues sois tan enemigos de la guerra”

Pedro de Oña, Arauco domado, pág. 401. Considero que es una clara alusión a las teorías sobre la guerra que se discutían a partir Francisco de Vitoria.

"Ladrones que a hurtar venis

el oro de nuestra tierra,

y disfrazando la guerra

decís que a Carlos servís,

¿que sujeción nos pedís?"

Lope de Vega, Arauco domado, 247.

30 «que antes moriré que aquí

pueda nadie poderoso

introducir por sí mismo,

supuesto que nos engaña

los tributos para España,

ni el crisma del bautismo."

Gaspar de Ávila; El gobernador prudente, pág. 44.

wa libertad aclamemos,

que vida sin ella es muerte,

porque el castellano fiero

conozca, penetre, alcance

de tu valor $y$ tu aliento

que sabes vencer pasiones

y sabes domar imperios"

González Bustos, Los españoles en Chile, pág. 3.

"¿Cuanto mejor es morir

con las armas peleando,

que vivir sirviendo un noble

como bestia y como esclavo?"

Lope de Vega, Arauco domado, pág. 277. 
como espiritual ${ }^{30}$, en el derecho natural que lleva a los hombres a la defensa de su tierra cuando ha habido una agresión ${ }^{31}$.

El interés de los españoles, personificado en D. García Hurtado de Mendoza, se centra en presentar la evangelización como el fin primordial, legitimación de la conquista ${ }^{32}$ y justa causa para la guerra, aludiendo el cambio de situación respecto a los desmanes anteriores, con la llegada del nuevo gobernador ${ }^{33}$.

En los razonamientos de unos y otro se pueden vislumbrar las tesis de Francisco de Vitoria sobre la guerra justa. En algunos párrafos puede parecer que los araucanos siguen la tesis vitoriana mientras Hurtado de

31 “La natural prematica ino manda

Que por la cara patria los mortales

Padezcan todo género de males,

Aunque hayan de morir en la demanda?

(..)

¿Paréceos que es más lícita la guerra

contra el pariente propio y el amigo

Que con extraño y áspero enemigo,

Tirano usurpador de vuestra tierra?"

Pedro de Oña, Arauco domado, pág. 411.

32 Caup., «En que funda quisiera

saber, esta acción primera

del dominio de tu Rey?

D. García: En instruiros la Ley

de Dios, que es la verdadera"

Gaspar de Ávila, El gobernador prudente, pág. 87.

${ }_{33}$ "Bien se que os han enojado

los tributos que han impuesto

los que hasta aquí han gobernado,

y que deseais por esto,

redimir vuestro cuidado.

Esta razón nos condena,

pero fue por culpa ajena

y con su dueño acabó,

pues vengo a traeros yo

el alivio desta pena.

$Y$ de haber introducido,

su jurisdicción mi Rey

supuesto que os ha instruido

preceptos de justa ley,

con justo derecho ha sido.

Si el Papa deve instruir,

también mi rey oprimir

con fuerza, y tienen los dos,

como inmediatos de Dios,

poder para reducir."

Ibidem, pág. 72. 
Mendoza presenta la oficialista ${ }^{34}$; sin embargo en el momento en el que se desarrollan los hechos y posteriormente, cuando escriben los distintos autores la recepción de la postura de Vitoria en la legislación era casi plena ${ }^{35}$. Por otro lado, algunas de la tesis de Vitoria son acogidas por don García, entre ellas la elección voluntaria (autodeterminación), que siempre es el primer cauce que utiliza ${ }^{36} 0$ la propagación de la religión cristiana, como se ha expuesto en líneas anteriores. No obstante, también se intenta justificar la dominación por títulos no recogidos por Vitoria, como la idolatría o el canibalismo, principalmente en la obra de Pedro de Oña. No obstante, esta mezcolanza de ideas, en parte se debe a que por encima de todo se quiere dar la imagen de un gobernador leal a su rey ${ }^{37}$, que en última instancia da sentido a la lucha. Por otra parte, en algunos puntos la imagen que se recoge de Hurtado de Mendoza va más allá de los argumentos de Francisco de Vitoria, especialmente en la represión del vencido después de la victoria ${ }^{38}$, abogando $D$. García por la magnanimidad, como lo hizo insistentemente en otros aspectos del trato a los indios ${ }^{39}$.

3. Aproximación al pensamiento de García Hurtado de Mendoza sobre la guerra y el ejercicio de su cargo:

En una carta de 10 de enero de 1558, dirigida a Felipe II, el gobernador relata cómo

\footnotetext{
34 Lerzund, P. C., La conquista de Chile en el teatro del Siglo de Oro. New York 1979, 285299, (reprografiada)

${ }_{35}$ Vid., PÉrez-Prendes, J. M., "La solución legal de la "duda indiana"', Actas del primer simposio sobre La ética en la conquista de América (1492-1573). Salamanca 1984, págs. 505509.

36 Pedro de Oña, Arauco domado, pág. 369.

${ }^{37}$ Luis de Belmonte y otros, Algunas hazañas..., pág. 497

38 Vid., TORREs LÓPEZ, M. «La doctrina de Santo Tomás sobre la guerra justa y sus influencias en la de Francisco de Vitoria", en Anales de la Facultad de Filosofía y Letras de la Universidad de Granada, IV (1928), págs. 23-24.

39 "Y que tengais por colmo de la gloria

Usar con el vencido de clemencia

De suerte que al furor no deis licencia,

Para manchar con sangre la victoria:

Que así resonará vuestra memoria

En cuanto ilustra el sol con su presencia,

Y no pondreis la mano en cosa alguna

Donde la suya os niegue la fortuna"

Pedro de Oña, Arauco domado, pág. 394.
} 
"vinieron a paz algunos caciques y repartimientos comarcanos á la Concibción y con ellos; no obstante los robos y muertes y destruiciones que han hecho en los que en esta tierra han estado, envié á decir á los de Arauco la clemencia de $V$. M. manda que se tenga en ellos, y que emendado lo de adelante la tendría yo en su Real nombre, y por no querello hacer sin tomalles cosa ninguna no lo demás que fuese menester para nuestro sustento, ni hacelles otro daño alguno entré en su tierra, y avisado dello y ayudados de secreto por los de la Concibción que estaban en paz, salieron á mi dos leguas antes que llegase á ella el pasaje de un río grande, que dicen Biobio, donde los desbaraté" ${ }^{40}$.

A pesar de las buenas intenciones que parecía tener el embajador enviado por los araucanos y de la actitud del gobernador, lo cierto fue que se trataba de una dilación en la guerra y una forma de conseguir información del enemigo.

Declaraciones en el mismo sentido se recogen en otras cartas dirigidas al rey, como la de 26 de febrero de 1590:

«De Chile he tenido nueva que luego que llego a aquel reyno la mi venida hauian enpezado a salir de paz algunos casiques y asi creo que quando sepan que escierta saldran los mas de ellos con los quales entiendo enbiar a tratar de algun buen mediio y concordia aunque sea dexandolos en mas libertad que la que tienen los demas que con esto se asegurara aquella costa de los yngleses y se escusara lo mucho que se gasta la Real hacienda de Vuestra Magestad (...).

El deseo de los yndios y españoles de chile es de que yo vaya a aquellas prouincias y cierto si me hallara con fuerças que suplicara a Vuestra magestad me diera licencia para hazerlo (porque quisiera mucho acabar aquella guerra por mi persona) y dexar la tierra en la quietud que aora $X X X$ años pues ademas de que en ellos fuera nuestro señor y Vuestra magestad servidos tengo a aquel Reyno particular adicion conla qual acudire siempre a socorrerle y a rremediar sus necesidades como me lo manda Vuestra Magestad mas estoy muy viejo y achacoso y cansado de la prolixa y travajosa jornada y he hallado muchos negocios represados que conviene remediar y poner en forma" ${ }^{41}$.

A partir de cartas como éstas, especialmente del periodo posterior de la época del virreinato de Perú, Campos Harriet ha esbozado la idea que Hurtado de Mendoza tenía sobre la guerra, considerando que compartía

40 Colección de Documentos Inéditos para la Historia de España, Tomo 24, págs. 217-20, apud..., LeRzUNDI, P. C., La conquista de Chile..., Ap. I, págs. 338-39.

4. Levillief, R., Gobernantes del Perú. Cartas y Papeles. Siglo XVI. Madrid 1926, tomo XII, pág. 104. 
el sentido «misional de la pacificación" de América, recogido en la política paternalista de los reyes y la legislación de Indias, pensando que no se justificaba la guerra si no había otro modo de obtener la pacificación y evangelización del indio. A pesar de ello, al final de su vida sintió grandes escrúpulos por los hechos que había realizado en la guerra de Arauco, de lo que dejó constancia en su testamento, ordenando una "restitución" o compensación para los indios que había combatido. Por otra parte, para él el triunfo en la guerra era una cuestión de honor, para cumplir el plan político de sus reyes ${ }^{42}$.

En este sentido Suárez de Figueroa resume los medios que él considera imprescindibles para una buena gobernación:

"Las armas, las leyes y el culto diuino en vna ciudad bien gouernada, no se pueden jamas separar" ${ }^{43}$.

Considero que la literatura no recoge esta idea de Hurtado de Mendoza, como no lo hace tampoco en su gestión como virrey del Perú, que sólo en el Arauco domado, de Pedro de Oña se recogen con cierta amplitud los disturbios acaecidos en Quito con motivo de la imposición de las alcabalas o en alguna otra obra como Las guerras de Chile, de Juan de Mendoza Monteagudo, se trata la negación a enviar recursos a Chile para continuar las guerras de Arauco ${ }^{44}$, sin embargo poco se recogen los motivos que Hurtado de Mendoza expone para tomar esta actitud, cuando él siempre consideró un asunto pendiente de su mandato como gobernador de Chile la pacificación de Arauco. En las cartas que escribe a Felipe II se refiere constantemente a este tema, quejándose de los abusos de los funcionarios en aquel territorio, motivo por el cual decide no enviar recursos y sustituir algunos de los cargos ${ }^{45}$.

Tampoco recoge la literatura temas como la visión de futuro que tenía Hurtado de Mendoza sobre el destino de América si no se remediaban los males que la acuciaban, especialmente de presión fiscal, mala gobernación y la falta de unión con España, pronosticando la independencia:

42 Campos Haraiet, F., Don García..., págs. 71-72.

43 Suárez de Figueroa, Hechos..., pág. 24.

44 Don Juan de Mendoza Monteagudo, Las guerras de Chile (Pub. con introducción, notas e ilustraciones por José Toribio Medina. Santiago de Chile 1888, pág. 19).

45 Carta de 17 de mayo de 1590, carta de 17 de mayo de 1592, carta de 15 de mayo de 1593, carta de 12 de abril de 1594, carta de 20 de enero de 1595 y otras, en LEVILLIER, R., Gobernantes del Perú..., tomo XII, págs. 163-65, 297-304, tomo XIII, págs. 23-27, 127-132, 200210 , respectivamente. 
"Hame parecido proponer a Vuestra Magestad que es muy necesario que estos Reinos tengan mucha union con esos y dependencia dellos y porque aca se dan y hacen ya las cosas que solian venir de España y la gente se va arraigando en la tierra y los naturales della creciendo y no solamente son hijos de los que de alla vinieron pero ay nietos y bisnietos dellos y asi temo que con el tiempo se ha de venir a olvidar y no ser menester aca las cosas de alla. Pareceme que importa mucho que Vuestra Magestad mande combocar a cortes estos Reinos con los de Castilla que las prematicas que salen de las cortes se imbien aca y ordene para que se guarden y cumplan y siendo esto por cedula de Vuestra Magestad se executaria con mas calor de lo que al presente se hace porque nunca vienen sino las que vnos particulares ynbian a otros" ${ }^{46}$.

\section{CONCLUSIÓN}

Comparando el papel que en la literatura tienen figuras como Hernán Cortés o en las crónicas las posturas de Almagristas y Pizarristas, resaltando las hazañas de su defendido y los horrores de su contrincante, el panegírico que se hace de García Hurtado de Mendoza no puede ser más mediocre y desvaído, de tal forma que desde la composición de la crónica de Mariño Lobera por Escobar y la obra de Suárez de Figueroa, pasando por el poema de Pedro de Oña hasta terminar por Lope de Vega, como el más genial en el terreno de lo posible, nos encontramos una y otra vez con una enumeración de hechos carentes de la más mínima convicción para crear la imagen que se pretendía olvidada y que se reproduce sin garra épica ni histórica.

Se intenta crear un "héroe" y en contraposición se pierde al político que posiblemente fue más de lo que hasta ahora se ha estudiado. No se resaltan sus continuas llamadas al rey en pro de un trato humano al indio pacificado y de su lucha por una "guerra justa", su voz en contra de la corrupción en el ejercicio de los cargos, su diplomacia en la provisión y destitución en los mismos $y$, en fin, su visión de futuro, prediciendo la pérdida de todo lo conseguido con tanto esfuezo si no se consideraba a América realmente parte integrante de España en todos los aspectos políticos e institucionales.

Hurtado de Mendoza no fue un personaje del relieve de Cortés, pero como contrapunto representó la imagen del buen funcionario, fiel en el ejercicio de su cargo, no exento de contradicciones, como es la fidelidad 
incondicional al rey y al mismo tiempo el eludir la normativa vigente en algunos casos, como el no permanecer en el lugar del cargo durante el juicio de residencia al que se le sometió tras su mandato como gobernador de Chile, si bien utilizó la «via directa» de apelación al rey que termina no sólo absolviéndolo, sino nombrándolo virrey del Perú; o cuando pretende modificar la composición de las juntas «ad hoc», a lo que el rey le responde prohibiéndoselo ${ }^{47}$; o el favorecimiento a sus soldados y allegados en los repartos o nombramientos para cargos, sobre lo que le llama la atención Felipe $\mathrm{II}^{48}$, de lo que se defiende aludiendo a la corrupción de los funcionarios. Pero por encima de estas excepciones se aprecia al fiel colaborador real, que antepone los intereses de la Corona a los propios, en un momento en el que el interés particular era el eje de la actuación, lo que queda claro en el momento de su partida de Chile, donde se reconoce que sale pobre e incluso con deudas, de modo que su buena actuación administrativa es reconocida, incluso, por sus "detractores", como Ercilla, que lo elogia en esta faceta:

«Puso el Gobernador luego llegando

en libertad las leyes oprimidas

la justicia y costumbres reformando

por los turbados tiempos corrompidas

y el exceso y desórdenes quitando

de la nueva codicia introducidas

todo lo demás por buen camino

dio la traza y asiento que convino".

(...)

“El cual en el turbado reino había

reformado los pueblos de manera,

que puso con solícito cuidado

la justicia y gobierno en buen estado»

Si realmente la figura de García Hurtado de Mendoza fue tan mediocre como la recoge Ercilla, en este caso la literatura fue un fiel reflejo de la realidad histórica, si Ercilla escondió al personaje por un interés particular, las obras que intentaron contradecirlo no consiguieron sino secundarlo, pero no lograron recuperar el mito, como pudo ocurrir con Cortés o con los Pizarro ${ }^{49}$.

47 Carta de 26 de febrero de 1590, Levillier, R., Gobernantes del Perú..., pág. 102. Cap. "De carta que su magestad escriuio al virrey del Peru en seys de Hebrero de nouenta y vno que manda no se inouen las juntas de guerra, sino que haga lo que hasta aqui se ha hechon, en Cedulario indiano recopilado por Diego de Encinas, l, págs. 305.

48 Ibidem., págs. 285-86.

49 Fernández, T., La imaginación americana en el teatro de Tirso de Molina, pág. 95. 